\title{
METHODS USED TO DEVELOP HYDROGEOLOGICAL MODEL OF LATVIA
}

\author{
Aivars Spalvins, Janis Slangens, Inta Lace, Kaspars Krauklis, Olgerts Aleksans \\ Environment Modelling Centre \\ Riga Technical University \\ 1/4 Meza str., Riga, LV-1007, Latvia \\ E-mail: emc@es.rtu.lv
}

\section{KEYWORDS}

Regional hydrogeological model, MODFLOW, boundary conditions, finite difference approximation.

\section{ABSTRACT}

In 2010-2012, the hydrogeological model (HM) of Latvia LAMO was established by scientists of Riga Technical University. The model will be applied for management of water resources of Latvia. The commercial program Groundwater Vistas $(\mathrm{GV})$ is used for running LAMO. GV includes the MODFLOW program that is worldwide applied for development of HM. Original methods were used to develop LAMO. They took part in performing the following tasks: creating geometry of HM; arrangement of various boundary conditions (digital terrain map, hydrographical network, infiltration flow, conditions on the HM shell surface); calibration process of HM. The methods have been proposed and developed by the RTU team. Because their appliance considerably improves quality of HM they may be of interest for modelers worldwide.

\section{INTRODUCTION}

This publication is focused on methods (Spalvins et al. 2011a) used to develop LAMO. For this reason, there only scarce data are presented about applications and construction of LAMO (Spalvins et al. 2012a; Spalvins et al. 2012d). LAMO simulates steady state average hydrogeological situation of Latvia. LAMO covers the $475 \mathrm{~km} \times 300 \mathrm{~km}$ area (Figure 1). For the current LAMO version, the land territory of Latvia and the area of the Gulf of Riga constitute the HM active area (Figure 2). The passive area represents border territories of the neighbouring countries. The active and passive areas are separated by the $4 \mathrm{~km}$ wide border zone that is used for fixing boundary conditions for the active area. However, LAMO is open for transboundary modeling projects. The neighbouring country must provide data for activating the HM area involved. To describe methods used for establishing LAMO, the basic mathematics of 3D-steady state models must be considered. By applying 3D-finite difference approximation, the $x, y, z$ - grid of HM is built using $(h \times h \times m)$ sized bocks ( $h$ is block plane size, $m$ is the variable thickness of a geological layer).
The model constitutes a rectangular $p$-tiered $x y$-layer system where $\mathrm{p}$ is the number of geological layers. For LAMO, $p=25, h=500$ metres.

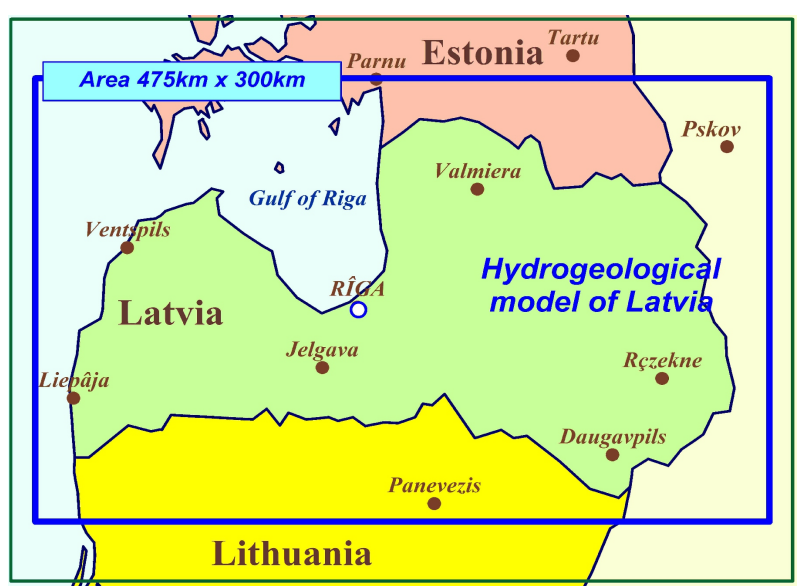

Figure 1: Location of LAMO

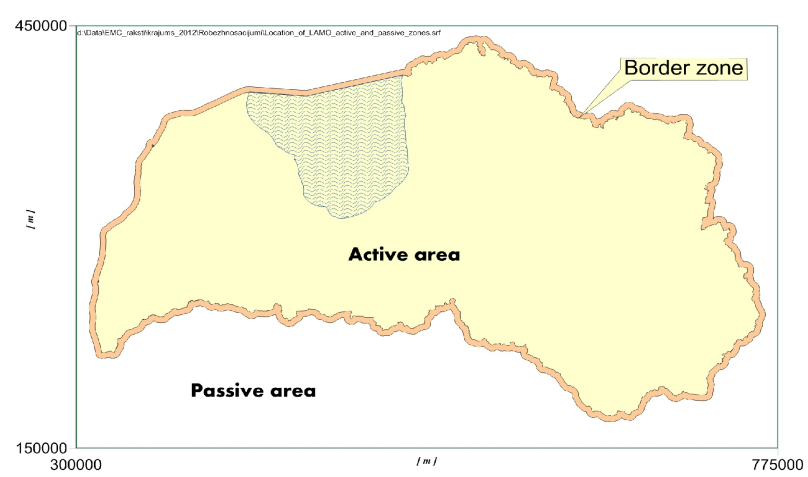

Figure 2: Location of LAMO active and passive areas

The modelling program controls the whole area of HM that contains also the passive area that takes no part in simulation. The active HM volume is enveloped by the border zone. Its outer vertical surface represents an impermeable shell that blocks transboundary groundwater flow. The relief (ground surface) and the 
lower side of the model are its geometrical top and bottom, accordingly.

Vector $\varphi$ of the piezometric head is the numerical solution of the boundary field problem which is approximated in nodes of the HM $x y z$-grid by the following algebraic expression:

$$
A \varphi=\beta-G \psi, \quad \mathrm{A}=A_{x y}+A_{z}
$$

where $A$ is the symmetric sparse matrix of the geological environment which is presented by the $x y$-layer system containing horizontal ( $A_{x y}$ - transmissivity) and vertical ( $A_{z}$ - vertical hydraulic conductivity) elements of the HM grid; $\psi$ - the boundary head vector: $\psi_{\text {rel }}, \psi_{\text {bot }}, \psi_{\text {out }}$ $\psi_{r i v}$ - subvectors of $\psi$ that represent boundary conditions of the HM top, bottom, border zone and rivers, accordingly; $G$-the diagonal matrix (part of $A$ ) assembled by elements, linking the nodes where $\varphi$ must be found with the points where $\psi$ is given (for $\psi_{t o p}, \psi_{b o t}$, $\psi_{\text {out }}$ these points are nodes of the HM grid); $\beta$ - the boundary flow vector. The elements $a_{x y}, a_{z}$ of $A_{x y}, A_{z}$ (or $g_{x y}, g_{z}$ of $G$ ) are computed as follows:

$$
a_{x y}=k m, \quad a_{z}=\left(h^{2} k\right) / m, m_{i}=z_{i-1}-z_{i}, \quad i=1,2, \ldots, p
$$

where $z_{i-1}, z_{i}$ are elevations, accordingly, of the top and bottom surfaces of the $\mathrm{i}$-th geological layer; $\mathrm{z}_{0}$ represents the ground surface elevation $\psi_{r e l}$-map with the hydrographical network included; $k, m$ are, respectively, elements of digital $m, k$-maps of the computed layer thickness and permeability.

If in some areas $m_{i}=0$, then the $i$-th layer is discontinuous. To prevent the "division by zero", in the $a_{z}$ calculation of (2), $m_{i}=0$ must be replaced by a small $\varepsilon>0$ (for LAMO, $\varepsilon=0.02$ metres).

The set of $z-$ maps represents the geometry of LAMO. Creating of these maps is the most burdensome task, because geometry of the geological environment of Latvia is very complex (Paskevicus 1997).

For the GV system (Environmental Simulations 2011), only z-maps serve as the initial ones and m-maps (thicknesses of layers) are obtained by GV itself.

In LAMO, the $\beta$-vector of flows is represented only by the withdrawal rates $\beta_{w}$ of well fields. It is not applied for usual simulation of recharge and evaporation flows on the HM top and the flows for other boundary surfaces.

For LAMO, the $\psi$-conditions were applied, instead of the $\beta$-flows due to the two main reasons:

- the $\psi$-conditions shortened the time needed for solving of (1), because they increased impact of the matrix $G$ as the diagonal dominance factor of $A$ (Strang 1976; Spalvins and Slangens 2007a);

- numerical values of the $\psi$-conditions were known much better than the ones of the $\beta$-flows.

For LAMO, the most important are boundary conditions $\psi_{\text {rel }}, \psi_{\text {out }} \psi_{\text {riv }}$.

\section{ARRANGEMENT OF BOUNDARY CONDITIONS}

\section{The digital relief map and the head distribution of the D2pr aquifer}

Appliance of piezometric boundary condition $\psi_{\text {rel }}$, on the HM top, instead of the conventional recharge and discharge (evaporation) flows $\left(\beta_{i n f}\right.$-conditions for infiltration flow) has considerably reduced the effort of developing HM, especially, of the large regional models where the groundwater infiltration distribution is very complex. It must account for numerous recharge and discharge areas. No modeller is able to guesswork the right $\beta_{\text {inf }}$ distribution for a large 3D HM (see Figure 6).

The $\psi_{\text {rel }}$-map was obtained by using the data of the Geospatial Information Agency of Latvia. Methods used to create the map are described in (Slangens and Krauklis 2011).

If the $\psi_{\text {rel }}-$ map is used, the flow $q_{\text {inf }}=q_{\text {aer }}$ passes through the aeration (vadose) zone:

$$
q_{a e r}=G_{a e r}\left(\psi_{r e l}-\varphi_{Q 2}\right)
$$

where $\varphi_{Q 2}$ is the computed head (subvector of $\varphi$ ) for the aquifer $Q_{2} ; G_{a e r}$ (diagonal submatrix of $G$ ) contains the vertical links $g_{a e r}$ of the aeration zone connecting the fixed $\psi_{\text {rel }}$ with the computed $\varphi_{Q 2}$. The expression (3) gives the ordinary result of $\mathrm{HM}$, when a $\psi$-condition is applied. As a rule, even the first run of HM provides feasible results for $q_{\text {inf }}$.

The vertical links $g_{a e r}$ of the diagonal matrix $G_{a e r}$ are controlling the $q_{a e r}$ distribution. Values $g_{a e r}$ depend on $h^{2}, k_{\text {aer }}$ and $m_{\text {aer }}$ (formula (2)) where $h=500, k_{\text {aer }}$ and $m_{\text {aer }}$ are, accordingly, the permeability and the thickness of the aeration zone. Initially, $k_{\text {aer }}$ and $m_{\text {aer }}$ are unknown. In nature, $m_{a e r}=\psi_{r e l}-\varphi_{Q 2}$ if $q_{a e r}>0$. If $q_{a e r}<0$ then, in LAMO, $m_{\text {aer }}=0.02$. The negative infiltration flow is caused mainly by lowlands, rivers and lakes. First, the following values of the aeration zone were tried: $m_{\text {aer }}=0.02[\mathrm{~m}], k_{\text {aer }}=10^{-6}[\mathrm{~m} /$ day $]$ (for recharge areas); $k_{\text {aer }}=10^{-4}[\mathrm{~m} / \mathrm{day}]$ (for areas of lakes and sea); $k_{a e r}=10^{-8}[\mathrm{~m} /$ day] (for areas of swamps).

To avoid iterative changes of the HM geometry, during calibration of HM, $m_{a e r}=0.02$ was kept constant, until the calibrated $q_{a e r}-$ flow was obtained (Figure 6) by adjusting the $k_{\text {aer }}$-distribution.

The piezometric head distribution $\psi_{D 2 p r}$ of the D2pr aquifer is applied as the boundary condition on the LAMO bottom surface $(z=25)$. The $\psi_{D 2 p r}$-map was obtained by using information of (Dzilna 1970). Influence of $\psi_{D 2 p r}$ is small, because it is separated from the HM body by the thick regional D2nr aquitard.

There are two reasons for application of this boundary condition: it may be useful if a modeller carries out research regarding the role of tectonic faults of the D2nr aquitard; the D2pr aquifer contains drinking water at the North-East part of Latvia. 


\section{Design of Boundary Conditions for the Border Zone}

Due to the presence of the HM passive area, the outer vertical surface of the boundary zone (shell) is impermeable for the transboundary groundwater flow. This factor distorts the natural groundwater regime in the close vicinity of the shell. Because the border zone width is $4 \mathrm{~km}$, the distortion is smaller on the inner surface of the zone. There exists the flow $q_{\text {out }}$ passing through this surface. One must try to recover the natural groundwater regime on this border surface. It can be done by fixing auxiliary boundary conditions $\psi_{\text {out }}$ on the middle line of the border zone. As the initial data for obtaining $\psi_{\text {out }}$ of aquifers, three data sources were used that provided linewise information: the $\psi_{\text {rel }}-$ map; $\psi_{\text {out }}$ for the D2ar aquifer; data extracted from the head distribution map of the prequaternary surface $\varphi_{\text {pree }}$. The $\varphi_{\text {preQ }}$-surface can provide only fragments of $\psi_{\text {out }}$ that can be observed from the bird's eye view. Special software was developed for extracting these data and for providing information that was necessary to design the interpolation tool that provided $\psi_{\text {out }}$ for aquifers of HM. Principles used to create the tool were reported in (Spalvins 2002). The design of the interpolation tool is based on the fact that a set of vertical links $a_{z}$ exists along the middle line of the border zone, which join the neighbouring aquifers. These links account both for the $k$ and $m$ parameters of the aquitards (formula (2)). If values of these links are considerably enlarged (at least, 1000 times), then this set of transformed vertical links behaves like a spatial interpolation device. It provides the unknown components of $\psi_{\text {out }}$ for aquifers. The above mentioned software detected these locations of the aquitards where they existed $(m \neq 0)$. For the $m=0$ areas, no transformation of the $a_{z}$-values was done.

Therefore, the $\psi_{\text {out }}$ boundary condition is obtained by $\mathrm{HM}$ itself, as follows: the components originated from the $\psi_{\text {rel }}, \varphi_{D 2 a r}, \varphi_{\text {pre }}-$-maps are fixed as the initial ones; the other components of $\psi_{\text {out }}$ are supported by the spatial interpolation tool that contains transformed $a_{z}$-links. The interpolator is not a part of the LAMO active volume and it can be used permanently. This feature is very useful during the HM calibration when the $a_{z}$-set gets changed and the $\psi_{\text {out }}$ conditions follow these changes.

\section{Rivers as boundary conditions}

The conditions $\psi_{r e l}, \psi_{D 2 p r}, \psi_{\text {out }}$ are fixed on the outer surfaces of HM and they exist in the nodes of the HM grid. The condition $\psi_{r i v}$ that represents water levels of rivers is attached to inner nodes of the HM grid via the set of the river bed conductance matrix $G_{r i v}$. The flow $q_{r i v}$ caused by rivers is given by the expression:

$$
q_{r i v}=G_{r i v}\left(\varphi_{r i v}-\psi_{r i v}\right)
$$

where the diagonal matrix $G_{r i v}$ is a part of $G$; $\psi_{r i v}$ is subvector of $\psi, \varphi_{\text {riv }}$ represents these nodes where the corresponding components of $\psi_{r i v}$ are attached via the links belonging to $G_{r i v}$. Components of $\psi_{r i v}$ belong to a set of points located outside the HM grid. The value of a single element $g_{r i v}$ of $G_{r i v}$ is presented by the formula:

$$
g_{r i v}=h w_{r i v} k_{r i v} / m_{r i v}
$$

where $h=500$ (plane step); $w_{r i v}$ - the river width; $k_{r i v}$, $m_{r i v}$-permeability and thickness of the river bed layer, accordingly; these parametres are unknown. Value $m_{r i v}=1$ was fixed and $k_{r i v}=0.008$ was found experimentally. Therefore, as the initial try, the formula (5) gives $g_{r i v}=4 w_{r i v}$. For LAMO, rivers are presented by their middle lines. The only exception is three artificial lakes of the Daugava river that have been formed by the Riga, Kegums, Plavinas hydro electrical power plants.

To obtain the $\psi_{r e l}$-conditions (formulas (4) and (5)), the following items were prepared: the xy -location of a river line; the long line profile (water levels $\psi_{\text {riv }}$ of a river along its line); the width $w_{r i v}$ of a river along its line; the z-attachment $g_{\text {riv }}$ of a river line.

The last item accounts for the fact that a river, on its run, may be joined with different geological layers. For example, the river Gauja runs through the Quaternary, the lower and upper Devonian layers. As about 200 rivers of Latvia are included in LAMO, no modeller is able to join them properly with a model. It was necessary to develop special software for preparing all data files that are needed for creating the $\psi_{\text {riv }}$-conditions.

The program also performed the search for the river $\mathrm{z}$-attachment. Presently, the empirical value $k_{r i v}=0.008$ is applied for all rivers. In nature, $k_{r i v}$ may be different not only for each river, but also for their fragments. The elements $g_{r i v}$ can be controlled also by changing the value of $m_{r i v}$ for formula (5). The task of finding more realistic $k_{\text {riv }}$ distributions is very complex, because observed in nature river flows of (4) must be used. Knowledge of these flows provides more exact estimates of the interaction between groundwater and rivers.

\section{CREATING OF Z-MAPS}

The most time consuming part of developing LAMO was preparation of the digital $\mathrm{z}$-maps that served as initial data for the GV system. For LAMO, most of the layers are outcropping (Figure 3). They are not continuous, and for this reason, they are not existing everywhere in the area of HM.

The geometry of LAMO is based on the geological information accumulated by the Latvian Environment, Geology and Meteorology Centre (LEGMC). The information includes stratigraphical data of boreholes, geological maps and descriptions regarding geology of Latvia. The LAMO geometry results in the set of $\mathrm{z}$-maps. It includes 26 surfaces for 25 geological layers presented in HM. The top surface of HM $(\mathrm{z}=0)$ is the digital hydrogeological relief of Latvia. It includes the 
hydrographical network (rivers, lakes, sea). The $z=1$ surface is the digital geological relief. It represents the ground surface elevations. For LAMO, this map accounts for depth of the sea and of three artificial lakes of hydro electrical power plants of the Daugava river. These two maps were created by using data provided by the Geospatial Information Agency of Latvia (Slangens and Krauklis 2011).

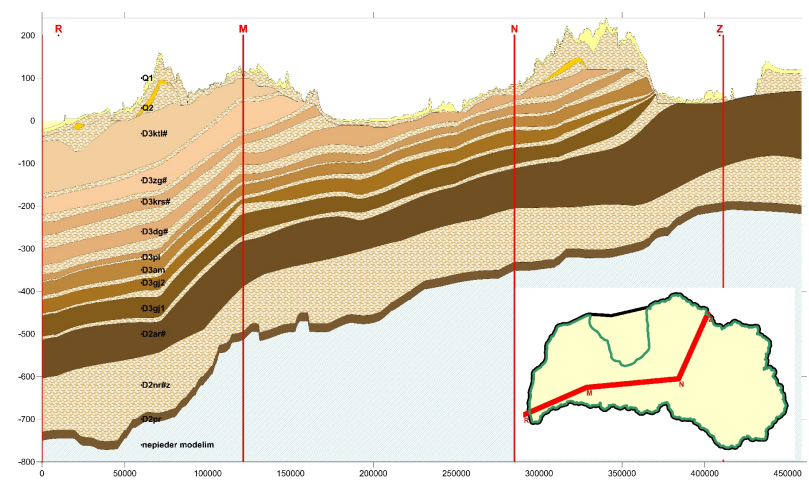

Figure 3: Geological cross section

The LEGMC specialists have prepared two important geological maps: the prequaternary surface preQ $(\mathrm{z}=6)$, the D2pr surface $(z=24)$. They are presented in Figure 4 and Figure 5, accordingly. The volumes of the Quaternary and primary geological layers are included between the $\mathrm{z}=0, \quad \mathrm{z}=6$ and $\mathrm{z}=24$ surfaces, correspondingly.

The most time consuming and difficult task (Spalvins et al. 2012b) was creating of $\mathrm{z}$-maps for the primary geological layers $(z=7,8, \ldots, 23)$. The basic stratigraphical information is carried by the boreholes and elevations of geological borderlines located on the preQ surface (Figure 4). The number of borehole data provided by LEGMC was large (about $20 \times 10^{3}$ ). However, very often data of boreholes were contradictory and it was not always possible to mend them. To reduce laborious work of checking the quality of all available borehole data, the set of representing geological cross sections was used where the chosen boreholes with trustworthy data were located. Deep boreholes were used, which provided stratigraphical data for all geological layers of the HM. As a rule, data gaps occurred along a section laterally and vertically (along a borehole axis). These gaps were filled by complementary data that were concordant with the existing borehole data. The $\mathrm{z}$-maps must always give positive thicknesses $m$. For this reason, the data of the sections must match this condition for layers of HM.

The $m=0$ areas of discontinuous layers also must be accounted for. It is done by using $m=\varepsilon=0.02$ instead of the zero thickness. There are three main reasons why the value of $\varepsilon$ must be small for the $m=0$ areas: geometrical distortions are minimal even if the number of overlaying $m=0$ areas is large (northern part of Latvia); transmissivity $T=\varepsilon k$ of aquifers is small even if their permeability $k$ is considerable; vertical conductivity $g_{v}$ of aquitards $g_{v}=h^{2} k / \varepsilon$ is large even if their permeability $k$ is small.

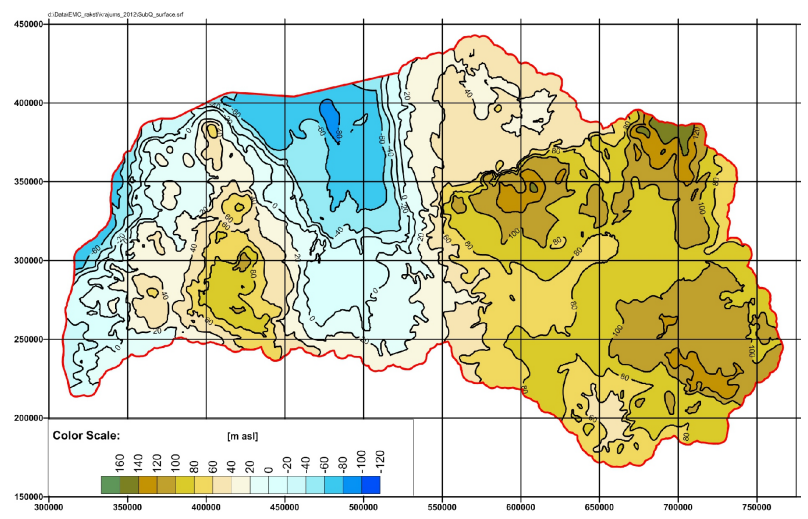

Figure 4: The prequaternary preQ surface $(z=6)$

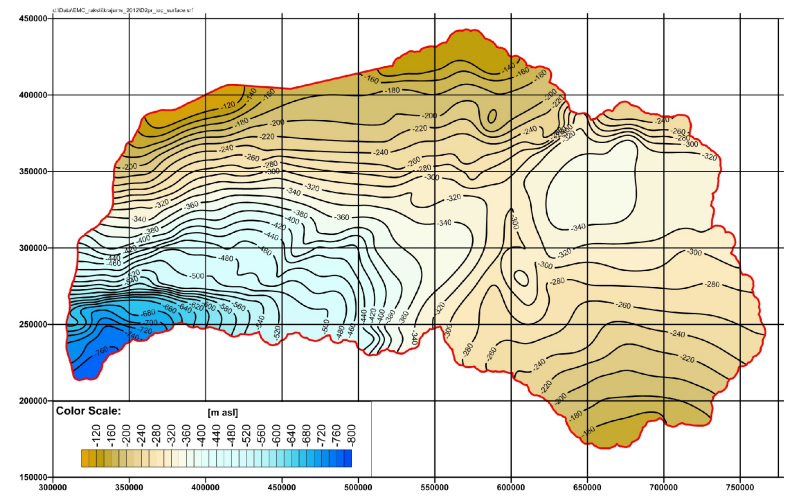

Figure 5: The D2pr top surface $(\mathrm{z}=24)$

If $\varepsilon=0.02$ then LAMO in its $m=0$ areas behave normally without special control measures for outcropping strata. This first stage of preparing data for $\mathrm{z}$-maps was performed by using the EXCEL system (Walkenbach 2009).

During the second stage of preparing $\mathrm{z}$-maps, the SURFER system (Golden Software 2010) was applied for obtaining a preliminarily version of the maps. The pointwise data prepared by EXCEL and spaced out pointwise data carried by the geological borderlines were used by SURFER.

Unfortunately, the SURFER system cannot provide good $\mathrm{z}$-maps, because of the following reasons: only pointwise data can be processed and their number is limited; the maximum - minimum principle is not insured for output data; the condition $\mathrm{m}>0$ is often violated; for the $\mathrm{m}=0$ areas, the requirement $\varepsilon=0.02$ is neglected. However, results obtained by SURFER provided valuable information for correcting possible errors of initial data.

The final version of $\mathrm{z}$-maps was obtained by the Geological Data Interpolation (GDI) system (Spalvins and Slangens 2007b). GDI uses points, lines and 
surfaces as data carriers. By interpolating pointwise data along lines of cross sections, much more informative concordant linewise data are obtained. GDI applies data of the cross sections, of the geological borderlines and of surfaces that are extracted from the preQ surface map (Figure 4).

For example, GDI reproduces the whole top surface of the D3ktl aquifer $(z=6)$. For other deeper layers, GDI uses fragments of surfaces that are enclosed between neighbouring borderlines on the preQ map.

Geometry of buried valleys and cuts of rivers in the body of primary geological layers were not simulated by LAMO. Accounting for the buried valleys is difficult and the data about the material that fills them are uncertain. The cuts of rivers were taken into account indirectly when rivers were input into LAMO (Spalvins et al. 2012c; Spalvins et al. 2011b)

\section{CALIBRATION PROCESS}

After all the necessary digital maps have been uploaded into the GV system, the model starts functioning and its calibration has to be accomplished.

Due to unavoidable limitations in the initial data, HM has no unique solution of (1). Calibration of HM is a controlled iterative process involving the addition of complementary data, until HM of a required quality is obtained. The quality is checked and maintained by tracing calibration targets. The following targets are usually set:

- original data should not be contradicted by data generated by HM; for example, the $\psi$ and $\varphi$ distributions of (1) must reproduce observed head values, the matrix A must incorporate observed permeability and geometrical features of $k$ and $\mathrm{z}$-maps, etc.;

- within the HM body, groundwater flows should not reach unnaturally large values (infiltration flow, flows regarding the hydrological network, etc.);

- results of HM must confirm the real hydrogeological situation, because formal agreement between computed and observed target data does not assure correct simulation; unfortunately, automatic calibration tools can sometimes provide almost worthless results.

The first and second targets are formal components of $\mathrm{HM}$, but the third target always requires subjective evaluation.

The calibration will never succeed if serious HM errors are present. Problems can include faults in data coordinates or values, mistakes in geological layer identification, mismatched reference data, unreliable boundary conditions or inadequate software.

The main subjects controlled during LAMO calibration were the k-maps of aquitards, because their filtration parameters were unknown.

A valuable instrument of searching for the right k-maps was distributions of vertical flows passing between neighbouring layers. The flows were computed by the SURFER program, as follows:

$$
q_{i, i+1}=0.73 \times 10^{6}\left(\varphi_{i}-\varphi_{i+1}\right) /\left(m_{i} / k_{i}+m_{i+1} / k_{i+1}\right)
$$

where $q_{i, i+1}$ was the vertical flow [mm/year] passing between the $\mathrm{i}$-th and $\mathrm{i}+1$-th layers. The formula holds even if both $m_{i}$ and $m_{i+1}$ are representing the "zero" $\mathrm{m}=0.02$ areas.

The k-maps have the following structure:

$$
k=k_{c} k_{\text {out }}
$$

where $k_{c}$ and $k_{\text {out }}$ are, accordingly, the core and outer diagonal k-matrixes. The $k_{c}$ matrix has no dimension and its basic value is 1.0. In the course of calibration, some areas of $k_{c}$ must be changed to values that are larger or smaller than the base value 1 . The matrix $k_{\text {out }}$ serve as the general factor for controlling the k-map for all nodes of an HM grid plane.

The most important is calibration of the $k_{\text {aer }}$-map for the aeration zone aer. Initially, its core matrix $k_{c}$ values are 100.0 and 0.01 for areas of lakes and swamp areas, respectively. The following formula was used for correcting the initial $k_{c}$ matrix

$$
\begin{aligned}
& k_{c}=k_{c} \mathrm{c}, \quad \mathrm{c}=1, \text { if } \Delta \leq M \text { or } c=(M / \Delta)^{n} \\
& \text { if } \Delta>M, \quad \Delta=\psi_{\text {rel }}-\varphi_{Q 2}
\end{aligned}
$$

where $c$ is the correction matrix; the parameter $M$ accounts for limitedness of the flow if $\Delta>M$ [metres].

For the areas where $\Delta>M$, the flow $q_{\text {aer }}$ gets limited, as follows:

$$
q_{a e r}=k_{a e r} M^{n} \Delta^{1-n} / 0.02
$$

If $n=1, q_{a e r}$ does not depend on $\Delta$. Then $q_{a e r}$ is controlled by the parameters $k_{a e r}$ and $M$. For LAMO, the empirical values $M=4$ and $n=0.75$ were used.

By using the formula (9), a rather smooth limitation of the infiltration flow $q_{a e r}$ was achieved for highland areas (Figure 6). Formula (9) was used also for other aquitards of HM.

During the calibration process, the thickness $m_{a e r}=0.02$ of the aer-zone is kept unchanged. As the final step, the real thickness $m_{\text {aer }}$ of must be obtained:

$$
\begin{aligned}
& m_{\text {aer }}=0.02 \text { if } \Delta \leq 0.02 \text { or } m_{\text {aer }}=\Delta \text { if } \Delta>0.02 \\
& \Delta=\psi_{\text {rel }}-\varphi_{Q 2}, \quad k_{\text {aer }}=\left(k_{\text {aer }}\right)_{c} c, \quad c=m_{\text {aer }} / 0.02
\end{aligned}
$$

where $\left(k_{a r}\right)_{c}$ is the calibrated value and $c$ is the correction matrix where its elements have values 1 and $m_{\text {aer }} / 0.02$ if $m_{\text {aer }}=0.02$ and $\Delta$, correspondingly.

If for the aer zone, its real thickness $m_{a e r}$ is obtained, then the thickness $\left(m_{Q_{2}}\right)_{c}$ decreases: $m_{Q 2}=\left(m_{Q 2}\right)_{c}-m_{a e r}$. It happens that $m_{Q 2}<0$. It means that the $\mathrm{Q} 2$ aquifer there is drained of. 


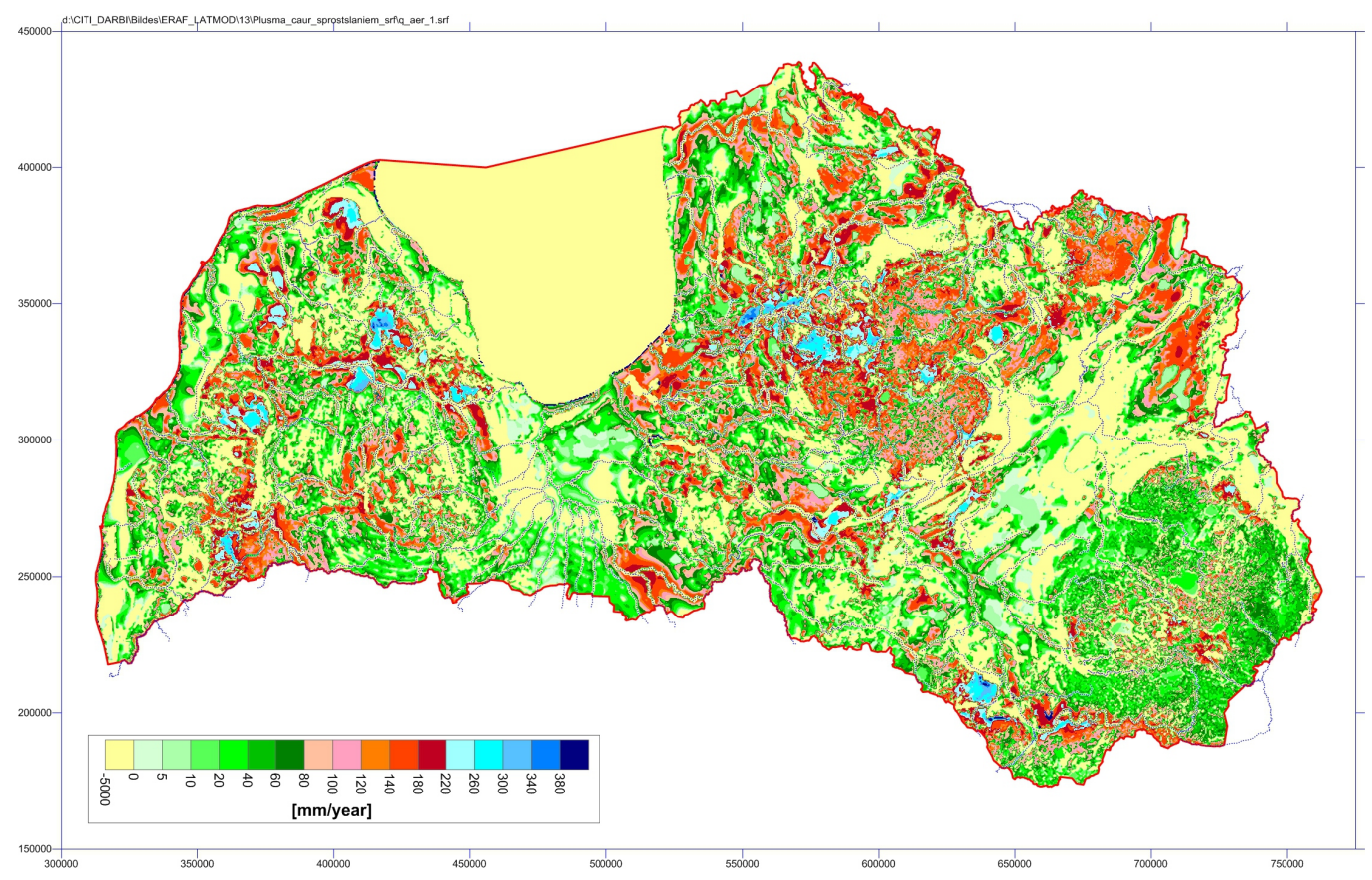

Figure 6: Calibrated $q_{a e r}$ distribution [mm/year]

To avoid considerable changes of the HM geometry, the assumption was made that, at least $0.2 \mathrm{~m}$ of the Q2 aquifer remained saturated. This assumption is hold if $m_{a e r}$ is changed, as follows:

$$
\begin{gathered}
\left(m_{a e r}\right)_{c}=m_{a e r} \text { if } m_{Q 2}>0.2 \text { or }\left(m_{a e r}\right)_{c}=\mathrm{c} m_{a e r} \\
\text { if } m_{Q 2} \leq 0.2, \quad c=\left(1+\left(m_{Q 2}-0.2\right) / m_{a e r}\right) ; \\
\text { when } c m_{\text {aer }}<0.02 \text { then }\left(m_{\text {aer }}\right)_{c}=0.02
\end{gathered}
$$

where $\left(m_{\text {aer }}\right)_{c}$ is the changed value of $m_{\text {aer }} ; c \leq 1$ is the

\begin{tabular}{|c|c|c|c|c|c|c|c|}
\hline $\begin{array}{l}\text { Code of } \\
\text { aquifer }\end{array}$ & $\begin{array}{l}\text { Top } \\
\text { flow }\end{array}$ & $\begin{array}{l}\text { Bottom } \\
\text { flow } \\
\text { glot }_{\text {bot }}\end{array}$ & $\begin{array}{l}\text { Inflow } \\
(2+3) \\
\mathrm{g}_{\text {in }}\end{array}$ & $\begin{array}{l}\text { Rivers } \\
\text { flow } \\
\text { q }_{\text {riv }}\end{array}$ & $\begin{array}{l}\text { Boun- } \\
\text { dary } \\
\text { flow } \\
\text { gout }\end{array}$ & $\begin{array}{l}\text { With- } \\
\text { drawal } \\
\text { flow } \\
\beta_{w}\end{array}$ & $\begin{array}{l}\text { Balance } \\
(4+5+ \\
+6+7)\end{array}$ \\
\hline 1 & 2 & 3 & 4 & 5 & 6 & 7 & 8 \\
\hline $\mathrm{Q} 2$ & 6782 & -3392 & 3390 & -3233 & -100 & -57 & 0 \\
\hline Q1 & 3392 & -3368 & 24 & -2 & -22 & 0 & 0 \\
\hline D3ktl & 3368 & -3171 & 197 & -193 & -3 & -1 & 0 \\
\hline D3zg & 3171 & -3102 & 69 & -42 & -22 & -5 & 0 \\
\hline D3krs & 3102 & -3078 & 24 & -12 & -8 & -4 & 0 \\
\hline D3dg & 3078 & -2465 & 613 & -592 & -16 & -5 & 0 \\
\hline D3pl & 2465 & -1965 & 500 & -413 & -70 & -17 & 0 \\
\hline D3am & 1965 & -1822 & 143 & -97 & -45 & -1 & 0 \\
\hline $\mathrm{D} 3 \mathrm{gj} 2$ & 1822 & -1437 & 385 & -271 & -89 & -25 & 0 \\
\hline D3gj1 & 1437 & -959 & 478 & -349 & -103 & -26 & 0 \\
\hline D2ar & 959 & -103 & 856 & -466 & -360 & -30 & 0 \\
\hline Model & 6782 & -103 & 6679 & -5670 & -838 & -171 & 0 \\
\hline $\mathrm{Q} 1+\mathrm{Q} 2$ & 6782 & -3368 & 3414 & -3235 & -122 & -57 & 0 \\
\hline $\begin{array}{l}\text { Primary } \\
\text { aquifers }\end{array}$ & 3368 & -103 & 3265 & -2435 & -716 & -114 & 0 \\
\hline
\end{tabular}
correction factor.

Table 1: Groundwater flow [thous. $\mathrm{m}^{3} / \mathrm{day}$ ] distribution
After dewatering of the Q2 aquifer, it was necessary to continue the calibration process.

Presently, the residual (difference between monitored and computed $\varphi$ values) does not exceed 1.7 metres (quadratic error) and 2\% (relative error).

The preliminarily version of flow distribution for LAMO aquifers is presented by Table 1 . There the total flow of rivers $q_{r i v}$ was the calibration target. Its rough value was obtained from the book (Dzilna 1970). It follows from Table 1 that the mean infiltration is $6782 \times 0.365 / 64.5=38 \mathrm{~mm} /$ year $\left(64.5\right.$ thous. $\mathrm{km}^{2}$ is land area of Latvia).

However, the calibration process of LAMO is not completed, because the links of the hydrographical network with the HM body are yet not adjusted properly.

\section{CONCLUSIONS}

The hydrogeological model of Latvia has been developed. To create the model, original methods were used to obtain maps representing complex geometry of the geological environmental of Latvia and to arrange various types of boundary conditions (digital relief map, conditions regarding hydrographical network, etc.). Effective methods were used to calibrate HM.

LAMO was developed in framework of the Project "Creating of hydrogeological model of Latvia to be used for management of groundwater resources and for evaluation of their recovery measures". The Project was co-financed by the European Regional Development Fund. 


\section{REFERENCES}

Dzilna, I. 1970. Resources, composition and dynamics of groundwater for the middle part of the Baltic area. Zinatne, Riga, p. 197 (in Russian)

Environmental Simulations, 2011. Inc. Groundwater Vistas. Version 6, Guide to using.

Golden Software. 2010. SURFER-9 for Windows. Users Manual.

Paskevicus, J. 1997. The geology of the Baltic republics. Vilnius university, Vilnius, p. 387, ISBN 9986-623-20-0

Slangens, J. and K. Krauklis. 2011. "Creating of digital relief map for regional hydrogeological model of Latvia". Scientific Journal of Riga Technical University in series "Computer Science". Boundary Field Problems and Computer Simulation, vol. 5, 49. (53)-th issue, Riga, RTU, 21-25

Spalvins, A.; J. Slangens; O. Aleksans; K. Krauklis; and I. Lace. 2012a. „Regional hydrogeological model of Latvia for management of its groundwater resources". In Proceedings 5-th International scientific conference Applied information and communication technologies, 24.26. april 2012, Jelgava, Latvia, 135-155 (CD)

Spalvins, A.; J. Slangens; I. Lace; K. Krauklis; O. Aleksans; and N. Levina. 2012b. "Methods and software tools used to designate geometry for regional hydrogeological model of Latvia". Scientific Journal of Riga Technical University Boundary Field Problems and Computer Simulation, 51-th issue, Riga, RTU, 13-19, ISSN 1407 - 7493

Spalvins, A.; J. Slangens; I. Lace; and K. Krauklis. 2012c. "Arrangement of boundary conditions for hydrogeological model of Latvia". Scientific Journal of Riga Technical University Boundary Field Problems and Computer Simulation, 51-th issue, Riga, RTU, 20-24, ISSN 1407 7493

Spalvins, A.; J. Slangens; I. Lace; K. Krauklis; V. Skibelis; O. Aleksans; and N. Levina. 2012d. "Hydrogeological model of Latvia, first results". Scientific Journal of Riga Technical University Boundary Field Problems and Computer Simulation, 51-th issue, Riga, RTU, 4-13, ISSN $1407-7493$

Spalvins, A.; J. Slangens; K. Krauklis; and I. Lace. 2011a. "Methods and tools to be applied for creating of regional hydrogeological model of Latvia". In Proceedings 25th European Conference on Modelling and Simulation, June 710, 2011, Krakow, Poland, 132-141, (ISBN: 978-09564944-2-9)

Spalvins, A.; J. Slangens; K. Krauklis; I. Lace; and V. Skibelis. 2011b. "Creating of initial data maps for regional hydrogeological model of Latvia". Scientific Journal of Riga Technical University in series "Computer Science". Boundary Field Problems and Computer Simulation, vol. 5, 50-th issue. Riga: RTU, 14-22

Spalvins, A. and J. Slangens. 2007a. "Impact of boundary conditions on quality of hydrogeological models". Proceeding of Riga Technical University in series Computer Science. Boundary Field Problems and Computer Simulation, vol. 5, 33(49)-th issue. Riga: RTU, 108-116

Spalvins, A., and J. Slangens, 2007b. "Reliable data interpolation method for a hydrogeological model conductivity matrix". In Proceedings Sixth International Conference on "Calibration and Reliability in Groundwater Modeling. Credibility in Modelling". Vol.2, 9-13 September 2007, Copenhagen, Denmark, 137-142

Spalvins, A. 2002. "Modelling as a powerful tool for predicting hydrogeological change in urban and industrial areas". K.W.F. Howard and R.G. Israfilov (eds.) Current problems of Hydrology in Urban Areas. Urban Agglomerates and Industrial Centres. Kluwer Academic Publishers. Printed in Netherlands, 57-75.

Strang, G. 1976. Linear algebra and its applications. Academic Press, New York, 373 INC.

Walkenbach, J. 2007. Excel 2007 Bible. Wiley Publishing, Inc., Indianapolis, Indiana, p. 808

\section{AUTHOR BIOGRAPHIES}

AIVARS SPALVINS was born in Latvia. In 1963, he graduated from Riga Polytechnic Institute (since 1990, Riga Technical University) as a computer science engineer. In 1967, A. Spalvins received the degree of Cand.Sc. (Dr.sc.). A. Spalvins has been with the university since 1958 (as a student) until now. His present scientific interests are computer modeling of groundwater flows and migration of contaminants. He is Director of the Environment Modelling Centre of the University. His e=mail address is: emc@cs.rtu.lv and the Centre Web-page is http://www.emc.rtu.lv

JANIS SLANGENS was born in Latvia. In 1969, he graduated from Riga Polytechnic Institute (since 1990, Riga Technical University) as a computer science engineer. In 1985, J. Slangens received the degree of Cand. Sc (Dr.sc.). Since 1969, he was with the the University. He is a senior researcher of the Environment Modelling Centre. His present scientific interests are computer modeling of groundwater flows. E-mail: emc@es.rtu.ly

INTA LACE was born in Latvia. In 1971, she graduated from Riga Polytechnic Institute (since 1990, Riga Technical University) as a computer science engineer. In 1995, I. Lace received the degree of M.sc. (applied computer science). Since 1991, she is a researcher of the Environment Modelling Centre, Faculty of Computer Science and Information Technology. E-mail: emc@cs.rtu.lv

OLGERTS ALEKSANS was born in Latvia. In 1979, he graduated from Vilnius State University (since 1988, The University of Vilnius) as a hydro geologist \& engineering geologist. In 2011, O. Aleksans received the Doctoral Degree in Geology at the University of Latvia. In the time period from 1997 till 2011 he was one of the company's VentEko Ltd founders and its Scientific Director. From 2011 he works as the researcher in the Environment Modeling Centre of Riga Technical University. E-mail: olgerts.aleksans@gmail.com

KASPARS KRAUKLIS holds M.Sc. degree of engineering science in computer systems from Riga Technical University (2007) and the certificate in Teaching of Engineering Sciences from RTU Institute of Humanities (2005). Currently he works as a researcher in the Environment Modelling Centre of Riga Technical University. E-mail: emc@cs.rtu.1v 